19

20

21

22

\title{
Fast and sensitive detection of genetically modified yeasts in wine
}

Carlos León ${ }^{1}$, Virginia García-Cañas ${ }^{1}$, Ramón González ${ }^{2}$, Pilar Morales ${ }^{2}$, Alejandro Cifuentes ${ }^{1, *}$

${ }^{1}$ Laboratory of Foodomics, Institute of Food Science Research (CSIC), Nicolas Cabrera 9, Campus de Cantoblanco, 28049 Madrid, Spain.

${ }^{2}$ Instituto de Ciencias de la Vid y del Vino (CSIC-UR-CAR), Madre de Dios 51, 26006 Logroño, Spain

Con formato: Español (alfab. internacional)

Con formato: Español (alfab. internacional) 


\section{ABSTRACT}

In this work, a novel screening methodology based on the combined use of multiplex polymerase chain reaction (PCR) and capillary gel electrophoresis with laser induced fluorescence (CGE-LIF) is developed for the fast and sensitive detection of genetically modified yeasts in wine. As model, a recombinant EKD-13 Saccaromyces cerevisiae strain was selected and different wines were prepared using either recombinant or conventional yeasts. Special emphasis is put on the yeast DNA extraction step, exploring different commercial and non-commercial methods, in order to overcome the important difficulty of obtaining amplifiable DNA from wine samples. To unequivocally detect the transgenic yeast, two specific segments of the transgenic construction were amplified. In addition, a third primer pair was used as amplification control to confirm the quality of the yeast DNA obtained from the extraction step. CGE-LIF provides high sensitivity, good analysis speed and impressive resolution of DNA fragments, making this technique very convenient to optimize multiplex PCR parameters and to analyze the amplified DNA fragments. Thus, the CGELIF method provided \%RSD values for DNA migration times lower than $0.82 \%(n=10)$ with the same capillary and lower than $1.92 \%(n=15)$ with three different capillaries, allowing the adequate size determination of the PCR products with an error lower than $4 \%$ compared to the theoretically expected. The whole method developed in this work requires less than one working day and grants the sensitive detection of transgenic yeasts in wine samples. 7 (1)

50

Keywords: transgenic yeast, multiplex PCR, capillary gel electrophoresis, genetically modified organisms, wine 


\section{INTRODUCTION}

The adoption of DNA recombinant technology has been considered the fastest growing trend in the history of agriculture, and, over recent years, the full potential of this modern biotechnology has been exploited for its application in modern plant breeding [1,2]. In addition to genetically modified (GM) crops, yeasts and lactic acid bacteria with a long history of use for food production have been subjected to genetic modification by genetic engineering mainly for improving the industrial processing or the quality of the final product [3-5]. The development of transgenic yeast strains using recombinant DNA technology has been the most recent step used by microbiologists to improve specific properties of wine [5]. Recently, two transgenic Saccharomyces cerevisiae strains have been commercialized in United States and Canada [6,7] to avoid the need of bacterial malolactic fermentation and the associated risk of bacterial spoilage in case of uncontrolled process (ML01 strain, [8,9]) and to reduce ethyl carbamate content (ECMo01 strain, [10]). Other genetic modifications in wine strains have been directed to: (i) reduce ethanol production [11-13]; (ii) release volatile aroma aglycones from grape glycosylated precursors [14-16]; (iii) improve the production of desirable volatile esters [17], the chemical stability of wine [18], and the yeast autolysis during the second fermentation of sparkling wines [19].

The development and use of genetically modified organisms (GMOs) for food applications are issues of intense debate and public concern that have pushed the European Union and other countries to establish strict regulations concerning different aspects of GMOs, including risk assessment, marketing, labeling and traceability. To verify the application of such regulations, it is necessary to develop analytical methodologies that can effectively detect GMOs in the food chain. In general, analytical procedures for GMO screening in food are based on DNA amplification by the polymerase chain reaction (PCR) technique. The ability of PCR to amplify specific DNA sequences in a complex DNA extract will depend on the integrity, quantity and purity of the DNA extract. These limiting factors define the amplificability of target DNA sequences by PCR-based 
methods, and are considered critical issues for GMO analysis in highly processed and complex food samples (chocolate, biscuits, etc.). In the case of wine samples, the presence of tannins, polyphenols and polysaccharides may interfere in DNA extraction and/or inhibit the amplification of isolated DNA [20-25]. In addition to the inhibitory effect of wine matrix on PCR, low quantity of DNA and degradation caused e.g., by biochemical and enzymatic action during fermentation and aging, are important constraints for DNA amplification in wine samples [26]. Strategies based on the use of long incubation periods for DNA precipitation or the use of large sample volumes have been applied to extract sufficient DNA from wine samples for subsequent PCR amplification [26-30]. On the other hand, different approaches have been suggested in order to overcome the inhibitory effect of wine matrix on PCR $[25,31]$. In this regard, attenuation of amplification by phenolic compounds has been addressed by the addition of molecules that act as polyphenols removers (polyvinylpyrrolidone, polyvinylpolypyrrolidone, activated charcoal, etc.) during the DNA extraction step. In other cases, separation methods, such as PVP-agarose gel electrophoresis purification, have been tailored to remove inhibitors from the DNA extracts from difficult samples as soil [24]. Therefore, an efficient extraction procedure is critical for DNA analysis from wine samples.

It has already been demonstrated that multiplex PCR is a suitable methodology for the simultaneous detection of specific targets in GMO-derived materials [32-35]. However, optimization of multiplex PCR is more complex than simplex PCR as the presence of more primer pairs in the reaction system reduces the robustness of the amplification process [32]. In many cases, the optimization and analysis of multiplex PCR reactions requires high sensitivity and resolution. In addition, sensitive analytical methodologies are necessary for the detection of recombinant yeasts in wine, as yeast DNA may be degraded and present in low concentration. In this regard, capillary gel electrophoresis with laser induced fluorescence (CGE-LIF) detection has proven to be a helpful separation technique during the optimization of multiplex PCR methods as well as for the simultaneous 
analysis of multiple GMOs in food samples [36]. The aim of this work is, therefore, to develop a novel methodology, based on the combined use of optimum DNA extraction, multiplex PCR amplification and CGE-LIF analysis for the fast and sensitive detection of genetically modified yeast strains in wine.

\section{MATERIALS AND METHODS.}

\subsection{Chemicals.}

All chemicals were of analytical reagent grade and used as received. Polyvinylpolypyrrolidone (PVPP) was from Applichem (Darmstadt, Germany); phenol was from LabClinics (Madrid, Spain), 2-propanol, chloroform and glucose were purchased to Scharlau (Barcelona, Spain); ethanol and isoamyl alcohol was from Merck (Darmstadt, Germany); and RNAse A was from Roche (Barcelona, Spain). Peptone and yeast extract were purchased from CONDA Pronadisa (Madrid, Spain). AmpliTaq Gold DNA polymerase, including GeneAmp PCR buffer II and, deoxynucleotides, $\mathrm{MgCl}_{2}$, were from Applied Biosystems (Madrid, Spain). Uracil DNA glycosylase was purchased from New England Biolabs (Berverly, MA). Oligonucleotides were purchased from Bonsai Biotechnologies (Alcobendas, Spain). Tris(hydroxymethyl)aminomethano (TRIS) and EDTA were obtained from Sigma (St. Louis, MO, USA); 2-hydroxyethyl cellulose (HEC, MWav 90000) was from Aldrich (Milwaukee, WI, USA); YOPRO-1 was from Molecular Probes (Leiden, The Netherlands). Separation buffer was stored at $4{ }^{\circ} \mathrm{C}$ and warmed at room temperature before use. Water was deionized by using a Milli-Q system (Millipore, Bedford, MA, USA).

\subsection{Samples.}

S. cerevisiae strain EC1118 is a conventional wine yeast strain commercialized by Lallemand Inc. (Montreal Canada). EKD-13 is a genetically modified strain of S. cerevisiae with an improved capacity to release mannoproteins to the media during the fermentation of the must [18]. Both $S$. cerevisiae strains were grown separately in YPD broth (2\% glucose, $2 \%$ peptone, $1 \%$ yeast extract) 
as negative and positive controls, respectively. $5 \mathrm{~mL}$ of YPD culture containing the reference yeasts were incubated for $24 \mathrm{~h}$ at $30^{\circ} \mathrm{C}$. Bottled wine, labelled as Petit Verdot, was donated by Laboratorio Agroalimentario de Jerez (Cádiz, Spain). For experimental production of control and recombinant wine samples, precultures were grown in YPD broth. Two types of grape must, including a blend of red wine grapes (musts 1 and 2) and a Graciano monovarietal red wine (must 3) were used for fermentation assays with EC1118 and the recombinant EKD-13 strains. Must were sulphited in origin to $30-50 \mathrm{ppm}$ of potassium metabisulphite. $200 \mathrm{~mL}$ of the unclarified musts (musts 1 and 3), or a must clarified by gentle centrifugation (must 2) were inoculated $1 \%$ in volume from a preculture in YPD grown for $48 \mathrm{~h}$ at $28^{\circ} \mathrm{C}$. All musts were fermented as for white wines (i.e., without maceration of skins and seeds), but the must differed in colour intensity with a deeper colour for the blend of red grapes (musts 1 and 2) than for the Graciano must (must 3). Fermentation was carried out at a controlled temperature of $25^{\circ} \mathrm{C}$ in erlemenyer flasks closed with fermentation locks filled with Vaseline oil. Fermentation kinetics was monitored as $\mathrm{CO}_{2}$ formation as estimated by daily recording loss of weight through the fermentation lock. Wine fermentation was considered complete after two days of constant weight. This was confirmed by HPLC analysis of the main fermentation metabolites (glucose, fructose, glycerol and ethanol). No further clarification was performed on the wine samples.

\subsection{DNA extraction and quantification.}

Different DNA extraction protocols (commercial and non-commercial) were evaluated in this work in order to obtain representative and reliable DNA extracts from the different types of samples.

\subsubsection{DNA extracts from yeasts.}

Extractions of DNA from cultured yeasts were performed using a commercial kit (MasterPure $^{\mathrm{TM}}$ Yeast DNA Purification Kit from Epicentre Biotechnologies, Madison, WI) following the instructions given by the manufacturer. Briefly, $300 \mu \mathrm{L}$ of Yeast Cell Lysis solution were added to 
the pellet, followed by $150 \mu \mathrm{L}$ of MPC Protein Precipitation Reagent and $0.5 \mathrm{~mL}$ of isopropanol. The DNA extract $(50 \mu \mathrm{L})$ was incubated with RNase $(1 \mu \mathrm{L})$ at $60^{\circ} \mathrm{C}$ for 30 min. After incubation, 1 volume of phenol/chloroform/isoamyl alcohol (25:24:1, v/v/v) was added and homogenized. After centrifugation at $14000 \mathrm{rpm}$ was performed, the upper phase was transferred to another tube and another extraction with chloroform/isoamyl alcohol (24:1, v/v) was done. Then, 0.1 volumes of $3 \mathrm{M}$ sodium acetate $(\mathrm{pH}$ 5.2) and 2 volumes of ethanol were added to the upper phase collected. The solution was kept at $-20{ }^{\circ} \mathrm{C}$ for $2 \mathrm{~h}$. The precipitate was collected by centrifugation at $14000 \mathrm{rpm}$ for $10 \mathrm{~min}$ and washed with $70 \%$ ethanol. The remaining ethanol was evaporated at room temperature and the pellet was dissolved in $50 \mu \mathrm{L}$ TE buffer that is composed of $10 \mathrm{mM}$ Tris- $\mathrm{HCl}$ and $1 \mathrm{mM}$ EDTA at $\mathrm{pH}$ 8.0.

\subsubsection{DNA extracts from wines.}

Several DNA extraction protocols were evaluated to amplify DNA from wine samples. The experiments were done using Petit Verdot as a model wine sample trying to obtain DNA of good quality and yield in order to get a sensitive amplificability of the $m r p 2$ gene by PCR. Briefly, $15 \mathrm{~mL}$ of the wine sample were centrifuged $\left(10000 \mathrm{rpm}\right.$ for $5 \mathrm{~min}$ at $\left.5{ }^{\circ} \mathrm{C}\right)$ to recover the solid parts in suspension. DNA extraction from the solid parts (pellets) was attempted using three different methods ( $\mathrm{A}, \mathrm{B}$ and $\mathrm{C}$, see below). Alternatively, during method optimization, the following procedure was also assayed as sample pre-treatment in order to remove potential inhibitors from the sample. Briefly, the solid part (pellet) was resuspended in $2 \mathrm{~mL}$ water and homogenized by pipetting. The suspension was centrifuged (14000 rpm for $5 \mathrm{~min}$ at room temperature) and the supernatant was discarded. This washing step was repeated twice. After washing, $1 \mathrm{~mL}$ of a $10 \%$ (w/v) PVPP aqueous suspension was added to the pellet. After homogenization by vortexing, the tube was incubated at room temperature for $5 \mathrm{~min}$. Then, the suspension was centrifuged (14000 rpm for 10 min at room temperature) and the supernatant was discarded. The DNA from the pellet was then subjected to extraction by Method A, B and $\boldsymbol{C}$ (see next). Method A: DNA was extracted 
185 from the pellet using the aforementioned commercial kit from MasterPure ${ }^{\mathrm{TM}}$ Yeast DNA

186 Purification Kit and following the manufacturer instructions as described above. Method $\boldsymbol{B}$ and $\boldsymbol{C}$ :

187 These methods were based on the protocol described by Querol et al. [37] with some modifications.

188 The pellet was suspended in $0.5 \mathrm{ml}$ of $1 \mathrm{M}$ sorbitol-0.1 M EDTA, pH 7.5. Next, $20 \mu \mathrm{L}$ of a solution 189 of Zymolyase-20 (2.5 mg/ml) was added. The suspension was incubated at $37{ }^{\circ} \mathrm{C}$ for $90 \mathrm{~min}$, and 190 then centrifuged at $14000 \mathrm{rpm}$ for $2 \mathrm{~min}$. Next, the pellet was suspended in $500 \mu \mathrm{L}$ of $50 \mathrm{mM} \mathrm{TE}$ 191 buffer, $\mathrm{pH}$ 7.4. After suspension, $10 \mu \mathrm{L}$ of an aqueous solution containing $20 \%$ sodium dodecyl 192 sulfate was added and the mixture was incubated at $65{ }^{\circ} \mathrm{C}$ for $30 \mathrm{~min}$. The suspension was 193 incubated with RNase $(1 \mu \mathrm{L})$ at $60^{\circ} \mathrm{C}$ for $15 \mathrm{~min}$. Immediately thereafter, $200 \mu \mathrm{L}$ of $5 \mathrm{M}$ potassium acetate was added and the tubes were placed on ice for $5 \mathrm{~min}$. Then, the solution was centrifuged at $14000 \mathrm{rpm}$ for $15 \mathrm{~min}$. In Method B, supernatant was transferred to a fresh microcentrifuge tube, and the DNA was precipitated by adding 1 volume of 2-propanol. After incubation at room temperature for $5 \mathrm{~min}$, the tubes were centrifuged for $10 \mathrm{~min}$. The DNA was washed with $70 \%$ ethanol, dried at room temperature, and dissolved in $50 \mu \mathrm{L}$ of TE buffer. In Method $C$, supernatant was extracted with 1 volume of phenol/chloroform/isoamyl alcohol (25:24:1, v/v/v) and then, centrifuged at $14000 \mathrm{rpm}$ for $10 \mathrm{~min}$. The aqueous phase was transferred to a clean microcentrifuge tube and DNA was purified with QIAamp DNA Mini Kit columns from Qiagen (Madrid, Spain) following the manufacturers instructions. Finally, the DNA retained in the column was eluted with $50 \mu \mathrm{L}$ TE buffer.

\subsection{Oligonucleotide primers.}

Primer pairs were designed using Primer3 online software [38] according to unique and specific DNA sequences to EKD-13 yeast strain. Namely, two primers pairs (indicated as pairs $\mathrm{KmPF} / \mathrm{KmPR}$ and $\mathrm{KmTF} / \mathrm{KmTR}$ in Table 1) were designed to amplify short DNA sequences (within the range of 100-200 bp) for the recombinant $S$. cerevisiae EKD-13. In addition, a third primer pair (SCF1/SCR1 in Table 1) was used as amplification control of a 104 bp DNA fragment 
211 in mrp2 gene in S. cerevisiae genome [30]. The primer pairs were also tested using the PrimerList

212 software [39] to control their suitability to be used in a multiplex system. The oligonucleotides were purchased from Bonsai Technologies (Alcobendas, Spain).

\subsection{Simplex and multiplex PCR conditions.}

Amplification reactions were run in a Mastercycler gradient thermocycler, Eppendorf (Madrid, Spain). Initially, the efficiency of the primer pairs to amplify the target sequences were separately tested by performing simplex PCR reactions using $0.5 \mu \mathrm{M}$ of each primer pair, SCF1/SCR1, $\mathrm{KmTF} / \mathrm{KmTR}$ and $\mathrm{KmPF} / \mathrm{KmPR}$ and several genomic DNA extracts from cultured EC1118 or EKD-13 yeast strains. Reactions were carried out using a mixture containing $10 \mathrm{mM}$ Tris- $\mathrm{HCl} \mathrm{pH}$ 8.3, $50 \mathrm{mM} \mathrm{KCl,} 2.6 \mathrm{mM} \mathrm{MgCl}_{2}, 0.25 \mathrm{mM}$ dCTP, $0.25 \mathrm{mM}$ dGTP, $0.25 \mathrm{mM}$ dATP, $0.5 \mathrm{mM}$ dUTP, $0.25 \mathrm{U}$ of Uracil-DNA Glycosilase (UDG), $1 \mathrm{U}$ AmpliTaq Gold 1 polymerase, 50 ng genomic DNA and the primer pair concentration indicated above in a final volume of $50 \mu \mathrm{L}$. PCR reaction was preceded by an incubation period of $10 \mathrm{~min}$ at $37^{\circ} \mathrm{C}$ for UDG activity. The PCR program consisted of an initial denaturation step at $95^{\circ} \mathrm{C}$ for $10 \mathrm{~min}$ followed by 10 cycles, which involved a final elongation step at $72{ }^{\circ} \mathrm{C}$ for $10 \mathrm{~min}$. Multiplex reactions were carried out under the same conditions described for simplex PCR but including the three primer pairs at the following concentrations: $0.7 \mu \mathrm{M}$ SCF1/SCR1, $0.2 \mu \mathrm{M}$ KmTF/KmTR and $0.1 \mu \mathrm{M} \mathrm{KmPF} / \mathrm{KmPR}$. To confirm the absence of contaminant DNA in simplex and multiplex PCR reactions, blank (without DNA template) reactions were systematically carried out in all experiments. For multiplex PCR, the primers were premixed in order to minimize the analysis-to-analysis variability due to pipetting.

\subsection{CGE-LIF conditions.}

The analyses of reaction products from simplex and multiplex PCR amplifications were carried out in a PACE-MDQ (Beckman Coulter) equipped with an Ar+ laser working at $488 \mathrm{~nm}$ (excitation 
wavelength) and $520 \mathrm{~nm}$ (emission wavelength). Bare fused-silica capillaries with $75 \mu \mathrm{m}$ I.D. were purchased from Composite Metal Services (Worcester, England). Injections were made at the cathodic end using $\mathrm{N}_{2}$ pressure of $0.5 \mathrm{psi}$ for $40 \mathrm{~s}$ ( 1 psi=6894.76 Pa). The PACE-MDQ instrument was controlled by a PC running the 32 Karat Software from Beckman. Before first use, any uncoated capillary was preconditioned by rinsing with $0.1 \mathrm{M} \mathrm{HCl}$ for $30 \mathrm{~min}$. The following conditions were used for PCR products separations: Bare fused silica capillary with $60 \mathrm{~cm}$ total length, $50 \mathrm{~cm}$ effective length and $75 \mu \mathrm{m}$ I.D; separation buffer $(20 \mathrm{mM}$ Tris, $10 \mathrm{mM}$ phosphoric acid, 2 mM EDTA, $500 \mathrm{nM}$ YOPRO-1, and $4.5 \%$ HEC at pH 7.3); temperature of separation: 45 ${ }^{\circ} \mathrm{C}$; running electric field: $-217 \mathrm{~V} / \mathrm{cm}$. Between injections, capillaries were rinsed using water for 5 min followed by $0.1 \mathrm{M} \mathrm{HCl}$ for $4 \mathrm{~min}$, and separation buffer for $4 \mathrm{~min}$. At the end of the day, the capillary was rinsed with deionized water for $5 \mathrm{~min}$ and stored overnight with water inside. For accurate size determination of the DNA fragments from PCR reactions, an eCAP dsDNA 1000 Test Mix from Beckman Coulter was used in CGE-LIF analysis. This sample was diluted to a final concentration of ca. $200 \mathrm{ng} / \mu \mathrm{L}$ in TE buffer.

\section{RESULTS AND DISCUSSION}

\subsection{Optimization of the DNA extraction method.}

DNA extraction from pure cultures of EC1118 and EKD-13 strains in YPD media was successfully carried out using the commercial MasterPure ${ }^{\mathrm{TM}}$ kit. A first evaluation of the extracts obtained from $1.5 \mathrm{~mL}$ of pure culture of yeast using UV spectroscopy gave $\mathrm{OD}_{260 / 280}$ and $\mathrm{OD}_{260 / 230}$ values of 1.6 and 2.5, corresponding to extraction yields ranging from 200 to $350 \mathrm{ng} / \mu \mathrm{L}$, respectively. However, in the case of wine samples, the DNA extracts obtained showed very low yield and purity as determined by UV spectroscopy and agarose gel electrophoresis (AGE). To corroborate this point, all DNA extracts were tested to perform the PCR amplification of a specific sequence in $S$. cerevisiae genome using the SCF1/SCR1 primer pair. Electrophoretic results showed only positive amplification of the control sequence in the extracts obtained from cultured yeasts (Figure 1, lines 7 
and 8), whereas no detectable signals were obtained in the amplification of wine extracts (data not shown). These results demonstrate that in spite of the availability of commercial kits tailored for the extraction of DNA from specific organisms, such as yeast, there are critical factors related to the sample matrix, DNA integrity and abundance that will determine the suitability of an extraction method for a particular (food) sample.

In order to obtain yeast DNA extracts from wine samples with good yield and quality for the subsequent PCR amplification, three different protocols to extract DNA from bottled wine samples were initially investigated. Namely, the methods tested were a commercial kit (Method A), the Zymolyase method including 2-propanol precipitation (Method B), and the Zymolyase method combined with silica column purification (Method C). Extractions were performed using sample volumes of $15 \mathrm{~mL}$. To study the contribution of PVPP to the quality and yield of the extract, extractions were performed with addition of PVPP to the sample as described under Materials and Methods. As controls, extractions were also performed without PVPP addition. Extracted DNA using the three methods could not be visualized in ethidium bromide-stained agarose gels due to low extraction yields, that were close to or below the detection limit of AGE ( 50 ng dsDNA in polydisperse samples). Although Method B provided the highest yields (> $50 \mathrm{ng} / \mu \mathrm{L}$ ), a smear band typical of RNA impurities was visualized in the extracts obtained by this method. These results suggested a possible overestimation of DNA concentrations based on UV spectroscopy data, in the extracts obtained by Method B. Also, it could be seen that the extracts obtained without PVPP treatment provided values of $\mathrm{OD}_{260 / 230}$ lower than 0.4 , indicating the presence of contaminants (likely, phenolic compounds). In general, the addition of PVPP had a detrimental effect on the yields, obtaining DNA yield values ca. 10\%, 67\% and 78\% lower in the extracts obtained by Method B, A and C, respectively, than the yields obtained without PVPP. In spite of these results, the addition of PVPP to the wine samples was considered necessary in order to obtain DNA of sufficient quality as can be deduced from lines 1, 3 and 4 in Figure 1. However, partial or complete 
inhibition of the subsequent PCR amplification of the specific sequence in S. cerevisiae was observed in all the cases, probably due to the copurification of inhibitory substances (lines 2,5 and 6 in Figure 1), indicating the complexity and relevance of the DNA extraction step. As the three methods provided similar negative results during the PCR amplification, a further optimization of the DNA extraction conditions was carried out. Method A was chosen for subsequent optimization since it provided better extracts in terms of purity $\left(\mathrm{OD}_{260 / 230}>0.7\right.$ and non detectable RNA bands in AGE). Higher starting volume of wine sample was then assayed. In this case, increasing the sample volume to $50 \mathrm{~mL}$ improved the extraction yield about two-fold (from 20 to $44 \mathrm{ng} / \mu \mathrm{L}$ ) with acceptable $\mathrm{OD}_{260 / 280}$ values $(>1.7)$, and low $\mathrm{OD}_{260 / 230}$ values $(<1.0)$. Although DNA appeared as a weak smear along the electrophoretic line in AGE, indicating DNA degradation in the wine sample, the specific sequence of $S$. cerevisiae genomic DNA could be amplified and clearly detected in the extracts obtained under these conditions. Next, Method A was applied to the DNA extraction of the wine samples produced in our lab with EC-1118 and EKD-13 yeast strains to test the suitability of the method with other types of wine. However, all the attempts to amplify the same reference sequence in these new extracts failed. This could be due to the different composition of the wine samples, also noticeable during extraction by the higher size of the pellets. Consequently, Method A was adapted to the extraction of high volumes of sample by using double volume of extraction reagents than those indicated by the manufacturer of the kit. The rest of extraction conditions were the same as described before. Under these conditions, DNA extracts with high yields and purity values were obtained for most of the samples (see Table 2). Although the AGE results also showed some DNA degradation, the suitability of the method to provide PCR-quality extracts from wine samples was corroborated by the positive PCR amplification of the DNA from all the samples.

\subsection{Design and optimization of multiplex PCR for transgenic yeast (EKD-13 strain) detection.}

The most accepted strategy for GMO detection in food relies on the PCR amplification of a specific DNA sequence. In GM plants, PCR targets used for identification are based on event-specific 
elements that are unique for a transformation event. These are sequences that cover the border of the transgenic insert and the plant genome. These sequences, however, cannot be used for the detection of recombinant yeasts. Insertion of the transforming DNA into the yeast chromosome is easily achieved by homologous recombination between chromosomal sequences and the construction of interest. In contrast to the GM plants, the insertion of recombinant DNA in many recombinant yeast strains is directed to a specific locus by incorporating a cognate homologous genomic sequence into the vector or construction of interest. The size of an edge fragment specific for the target recombinant yeast would be too large for an efficient PCR amplification. In this case, the detection of recombinant yeasts can be approached by targeting junctions of contiguous transgenic elements. Consequently, the primers for the detection of EKD-13 strain were designed according to one of the recombinant constructs used for deletion of KNR4 gene in this recombinant strain. The construct is composed of KanMX4 coding sequence (from Escherichia coli DH5a), which provides resistance to geneticin, flanked by $K N R 4$ promoter and terminator sequences, homologous to those found in non-recombinant $S$. cerevisiae [40]. For construct-specific detection, a primer pair (KmPF/KmPR) was designed to span a junction segment covering the $K N R 4$ promoter and KanMX4 coding sequence (Table 1). To increase the specificity for the recombinant strain, the forward primer (KmPF) was devised to target the border of $K N R 4$ promoter and a short sequence, derived from the vector used for transformation (pDKNR4-3), located between promoter and coding sequence. The reverse primer (KmPR) was complementary to KanMX4 coding sequence. To unequivocally detect EKD-13 strain in samples, a second primer pair (KmTF/KmTR) was designed to target another specific segment of the same construction (Table 1). For this design, a reverse primer (KmTR) was selected to target a specific sequence derived from pDKNR4-3 vector and located between coding sequence and terminator, whereas the forward primer was designed to recognize KanMX4 coding sequence. In addition, a third primer pair (SCF1/SCR1) was used as amplification control of a $104 \mathrm{bp}$ fragment of $m r p 2$ nuclear gene that codes for a mitochondrial ribosome protein in S. cerevisiae (Table 1). The specificity of this sequence has been evaluated in 
12 species commonly found in wine and must and a total of 23 S. cerevisiae strains by Salinas et al. [30].

As can be seen in Figure 2A, a 104 bp well-characterized amplicon of $m r p 2$ gene sequence (peak $r$ ) was produced by PCR amplification using SCF1/SCR1 in the presence of genomic DNA from yeast. The specificity of the primer pairs designed in this study was determined by amplifying DNA extracted from cultured EKD-13 and EC-1118 strains with the designed KmPR/KmPF and KmTR/KmTF primers in simplex PCR format. Figures 2B and $\mathbf{C}$ show the CGE-LIF analysis of simplex PCR amplifications of each primer pair with genomic DNA extract from cultured EKD-13 strain. Moreover, as expected, these primers were not able to amplify DNA from conventional EC1118 strain (data not shown) corroborating the selectivity of this approach.

The length of the amplified DNA fragments was verified comparing their theoretical and experimental sizes. To do this, an equation was obtained co-injecting a mixture containing the three PCR products with a standard mixture of DNA fragments with known sizes and plotting the logarithm of the length (bp) of these known DNA fragments vs. the inverse of their migration time $(\log (\mathrm{bp})=4.27-43.86 / \mathrm{tm}(\mathrm{r}=0.991, \mathrm{n}=5))$. Migration times $\left(\mathrm{t}_{\mathrm{m}}\right)$ of the peaks were used to calculate the length of the PCR amplicons. The experimentally calculated length of the PCR products was 100, 170, and 193 bp (for peaks $r, t$, and $p$, respectively, see Figure 2). These values were in good agreement with the sizes theoretically expected (104, 174, and 199 bp, respectively), demonstrating that this PCR-CGE-LIF method provides accurate amplification and determination of the DNA fragments (calculated values showed an error $<4 \%$ compared to the theoretical values). An extra signal was systematically detected close to peak $p$ in amplifications carried out with the $\mathrm{KmPF} / \mathrm{KmPR}$ primer pair of samples containing EKD-13 strain genomic DNA. The detection of this extra peak can be explained by different reasons. For instance, minor signals can frequently result from slippage of DNA polymerase that produces either shorter or even longer PCR stutter 
products. More likely, the presence of this minor peak can be originated by impurities of the synthetic oligonucleotides used for amplification. In any case, the presence of this minor peak with a calculated size of $200 \mathrm{bp}$ did not preclude the detection of any specific PCR product.

Reproducibility of the described CGE-LIF procedure with a standard 100 bp DNA ladder was adequate for the purpose of this application. Calculated \%RSD values of up to $0.82 \%(\mathrm{n}=10)$ with the same capillary and up to $1.92 \%(n=15)$ with three different capillaries were obtained for DNA fragments of 100 and 200 bp-length.

A multiplex PCR method was next developed in order to reduce the number of reactions required to detect the transgenic yeast, trying to determine in a single analyses the three PCR amplicons. To attain this, DNA extracts from cultured yeasts were next amplified in one tube with a mixture of the six primers by multiplex PCR method. Figure 3A shows the CGE-LIF electrophoregram for the multiplex PCR amplification of a DNA extract from cultured EKD-13 strain under the same conditions of simplex PCR reactions, except for the concentration of primers $(0.5 \mu \mathrm{M}$ of $\mathrm{SCF} 1 / \mathrm{SCR} 1,0.1 \mu \mathrm{M} \mathrm{KmTF} / \mathrm{KmTR}$, and $0.1 \mu \mathrm{M}$ of $\mathrm{KmPF} / \mathrm{KmPR})$. As can be seen, under these conditions, no amplification was detected for the two shorter DNA fragments (i.e., 104 bp and 174 bp sequences) in multiplex format. Therefore, a further optimization of the multiplex PCR reaction parameters had to be carried out in order to obtain optimal amplification for all the DNA sequences under study. In this sense, since CGE-LIF provides accurate quantitative information, high sensitivity and high resolution, this technique can be conveniently used to adjust PCR parameters with confidence [41-43]. Accordingly, concentrations of SCF1/SCR1 and KmTR/KmTF primer pairs were adjusted in order to improve co-amplification of these PCR fragments. Figure 3B shows the electropherogram obtained once optimum triplex PCR amplification conditions were obtained (namely, $0.7 \mu \mathrm{M}$ SCF1/SCR1, $0.2 \mu \mathrm{M} \mathrm{KmTF/KmTR,} \mathrm{and} 0.1 \mu \mathrm{M} \mathrm{KmPF/KmPR}$ ).

\subsection{Analysis of wine samples by multiplex PCR-CGE-LIF.}


The suitability of the multiplex PCR-CGE-LIF method was tested analyzing wine samples obtained in separate vinification processes using conventional or transgenic yeast strains. The results are shown in Figure 4A-F. As can be seen, all the electropherograms of Figure 4 reveal the presence of peak $r$, which corresponds to the expected 104 bp mrp2 amplicon used as control, assuring that amplifiable DNA from $S$. cerevisiae has been obtained in all the extracts analyzed. Figures 4B, D and $\mathbf{F}$ show that in the electropherograms of the wine samples produced with transgenic EKD-13 strain, peaks $p$ and $t$, which correspond to the expected $174 \mathrm{bp}$ and $199 \mathrm{bp}$ amplicons, could be detected, whereas no peaks other than peak r could be observed in the analysis of the wine samples obtained with the non-recombinant yeast strain (Figure 4A, C and E). With regard to the effect of the sample matrix, as can be seen in Figure 4F, the analysis of wine obtained from non-clarified musts did not show significant differences compared to the corresponding wine samples obtained from centrifuged musts (Figure 4B). These results demonstrate the good performance of the multiplex PCR-CGE-LIF method even in wine obtained from non-clarified musts, in which background DNA is expected to be more abundant and complex.

In conclusion, a new multiplex PCR-CGE-LIF separation method is proposed for the detection of recombinant yeasts in wine samples. In addition, the extraction methodology described here is new, although based on the adaptation of a commercial kit for the extraction of PCR-quality yeast DNA from wine samples, including the addition of PVPP to obtain detectable amplification products. The usefulness of this multiplex PCR-CGE-LIF method was demonstrated detecting genetically modified yeasts in different wine samples. The method developed in this work allows the sensitive detection of transgenic yeasts in wine samples in less than one working day, with no need for additional yeast culturing steps.

\section{ACKNOWLEDGEMENTS}


This work was supported by a CSIC-Beckman Coulter contract and the CSIC project 200870I185.

421 Authors want to thank Dr J. Barcenilla for his help with the yeast cultures. We are grateful to Rosa

López (CIDA, Gobierno de La Rioja), for providing must samples for experimental wine production. We want to thank J. M. Mateo for providing bottled wine samples (Laboratorio

Agroalimentario y Estación Enológica de Jerez, Cádiz). C. Leon wants to thank Comunidad

Autónoma de Madrid for a grant.

\section{REFERENCES}

[1] World Health Organization, Food safety (2002). http://www.who.int/fsf/GMfood.

[2] V. García-Cañas, C. Simó, C. León, E. Ibáñez, A. Cifuentes, Mass Spectrom. Rev. in press.

[3] I.S. Pretorius, Yeast 16 (2000) 675.

[4] W. Sybesma, J. Hugenholtz, W.M. De Vos, E.J. Smid, Electron. J. Biotechn. 9 (2006) 1.

[5] E. Cebollero, D. Gonzalez-Ramos, L. Tabera, R. Gonzalez, Biotechnol. Lett. 29 (2007) 191.

[6] Food and Drug Administration, FDA Notice 000120 (2003).

http://www.accessdata.fda.gov/scripts/fcn/gras_notices/grn000120.pdf.

Drug Administration,

FDA Notice

000175

(2005).

443 http://www.accessdata.fda.gov/scripts/fcn/gras_notices/grn000175.pdf.

[8] J.I. Husnik, H. Volschenk, J. Bauer, D. Colavizza, Z. Luo, H.J.J. van Vuuren, Metab. Eng. 8 (2006) 315 .

[9] J.I. Husnik, P.J. Delaquis, M.A. Cliff, H.J.J. van Vuuren, Am. J. Enol. Vitic. 58 (2007) 42.

[10] J. Coulon, J.I. Husnik, D.L. Inglis, G.K. Van Der Merwe, A. Lonvaud, D.J. Erasmus, H.J.J. 
[11] S. Michnick, J.L. Roustan, F. Remize, P. Barre, S. Dequin, Yeast 13 (1997) 783.

[12] F. Remize, J.M. Sablayrolles, S. Dequin, J. Appl. Microbiol. 88 (2000) 371.

[13] J.M. Eglinton, A.J. Heinrich, A.P. Pollnitz, P. Langridge, P.A. Henschke, M. de Barros- Lopes, Yeast 19 (2002) 295.

[14] P. Sánchez-Torres, L. González-Candelas, D. Ramón, FEMS Microbiol. Lett. 145 (1996) 189.

[15] M.A. Ganga, F. Pinaga, S. Valles, D. Ramon, A. Querol, Int. J. Food Microbiol. 47 (1999) 171.

[16] P. Manzanares, M. Orejas, J.V. Gil, L.H. De Graaff, J. Visser, D. Ramón, Appl. Environ. Microbiol. 69 (2003) 7558.

[17] M. Lilly, M.G. Lambrechts, I.S. Pretorius, Appl. Environ. Microbiol. 66 (2000) 744.

[18] D. Gonzalez-Ramos, E. Cebollero, R. Gonzalez, Appl. Environ. Microbiol. 74 (2008) 5533.

[19] E. Cebollero, A. Martinez-Rodriguez, A.V. Carrascosa, R. Gonzalez, FEMS Microbiol. Lett. 246 (2005) 1.

[20] A.A. Ogunjimi, P.V. Choudary, FEMS Immunol. Med. Microbiol. 23 (1999) 213.

[21] D.V. Jobes, D.L. Hurley, L.B. Thien, Taxon. 44 (1995) 379.

[22] J.E. Maliyakal, Nucleic Acids Res. 20 (1992) 2381.

[23] Y. Tsai, B.H. Olson, Appl. Environ. Microbiol. 58 (1992) 2292.

[24] C. Young, R.L. Burghoff, L.G. Keim, V. Minak-Bernero, J.R. Lute, S.M. Hinton, Appl. Environ. Microbiol. 59 (1993) 1972.

[25] I.G. Wilson, Appl. Environ. Microbiol. 63 (1997) 3741.

[26] F. Savazzini, L. Martinelli, Anal. Chim. Acta 563 (2006) 274. 
[28] R. Siret, O. Gigaud, J.P. Rosec, P. This, J. Agr. Food Chem. 50 (2002) 3822.

[29] M.M. Baleiras-Couto, J.E. Eiras-Dias, Anal. Chim. Acta 563 (2006) 283.

Con formato: Español (alfab. 495

[30] F. Salinas, D. Garrido, A. Ganga, G. Veliz, C. Martínez, Food Microbiol. 26 (2009) 328.

[31] M.C. Simon, D.I. Gray, N. Cook, Appl. Environ. Microbiol. 62 (1996) 822.

[32] V. García-Cañas, A. Cifuentes, R. González, Crit. Rev. Food Sci. Nutr. 44 (2004) 425.

[33] M. Hernández, D. Rodríguez-Lázaro, D. Zhang, T. Esteve, M. Pla, S. Prat, J. Agr. Food Chem. 503 53 (2005) 3333.

[34] Y. Zhou, Y. Li, X. Pei, Chromatographia 66 (2007) 691.

[35] J. Xu, S. Zhu, H. Miao, W. Huang, M. Qiu, Y. Huang, X. Fu, Y. Li, J. Agr. Food Chem. 55 508 (2007) 5575 .

[36] V. García-Cañas, R. González, A. Cifuentes, TrAC - Trends Anal. Chem. 23 (2004) 637.

[37] A. Querol, E. Barrio, T. Huerta, D. Ramon, Appl. Environ. Microbiol. 58 (1992) 2948.

[38] S. Rozen, H.J. Skaletsky, in S. Krawetz, S. Misener (Eds.), Bioinformatics Methods and Protocols: Methods in Molecular Biology. Humana Press, New Jersey, 2000, pp. 365.

[39] R. Kalender, Primer Digital (2010). http://primerdigital.com/tools/. Con formato: Italiano (Italia)

Con formato: Español (alfab. internacional) 
[42] V. García-Cañas, A. Cifuentes, J. Agr. Food Chem. 56 (2008) 8280. 


\section{FIGURE LEGENDS}

Figure 1 Electrophoretic analysis in a $2 \%(\mathrm{w} / \mathrm{v})$ agarose gel of the amplifications performed with SCF1/SCR1 primer pair in DNA extracts from $15 \mathrm{~mL}$ Petit Verdot wine using different conditions: Lines 1, 3, and 4 correspond to the samples treated with PVPP; and lines 2, 5, and 6 correspond to untreated controls. Lines 1 and 2, samples were extracted using Method A; lines 3 and 5, samples were extracted using Method B; lines 4 and 6, samples extracted using Method C. Lines 7 and 8, amplified DNA extracts obtained from $1.5 \mathrm{~mL}$ cultured EC-1118 strain using a commercial kit and manufacturer's protocol

Figure 2 CGE-LIF electropherograms of amplified DNA from transgenic EKD-13 cultured yeast using simplex PCR with different primer pairs: A) SCF1/SCR1; B) KmTR/KmTF; and C) KmPR/KmPF. CGE-LIF separation conditions: uncoated fused-silica capillary with $60 \mathrm{~cm}$ total length, $50 \mathrm{~cm}$ effective length and $75 \mu \mathrm{m}$ I.D.; separation voltage: $-13 \mathrm{kV}$, running temperature $45^{\circ} \mathrm{C}$. Injection time $40 \mathrm{~s}(0.5 \mathrm{psi})$. BGE: $20 \mathrm{mM}$ Tris, $10 \mathrm{mM}$ phosphoric acid, $2 \mathrm{mM}$ EDTA, 500 nM YOPRO-1, and 4.5\% HEC at $\mathrm{pH} 7.3$.

Figure 3 CGE-LIF analysis of multiplex PCR reactions performed with DNA from transgenic EKD-13 cultured yeast and the three primer pairs at the following concentrations: A) $0.5 \mu \mathrm{M}$ SCF1/SCR1, $0.1 \mu \mathrm{M} \mathrm{KmTR/KmTF,} 0.1 \mu \mathrm{M}$ KmPF/KmPR; B) $0.7 \mu \mathrm{M}$ SCF1/SCR1, $0.2 \mu \mathrm{M}$ KmTR/KmTF, $0.1 \mu \mathrm{M} \mathrm{KmPF/KmPR.} \mathrm{CGE-LIF} \mathrm{separation} \mathrm{conditions} \mathrm{as} \mathrm{in} \mathrm{Figure} 2$

Figure 4 Electrophoretic analysis of triplex PCR amplifications from different wines: A, C and E) musts fermented with the conventional EC1118 strain; B, D and F) musts fermented with transgenic EKD-13 strain. Wine produced from must 2 (A and $\mathrm{B})$, must $3(\mathrm{C}$ and $\mathrm{D})$ and must $1(\mathrm{E}$ and $\mathrm{F})$. CGE-LIF separation conditions as in Figure 2 
559 Table 1. Primers used for simplex and multiplex PCR amplifications of DNA extracts from culture 560 yeasts and wine samples.

\begin{tabular}{|c|c|c|}
\hline Name & Sequence (5'-3') & Ref. \\
\hline $\begin{array}{l}\mathrm{KmPF} \\
\mathrm{KmPR}\end{array}$ & $\begin{array}{l}\text { ATCCCCCATGGCTATCACGA } \\
\text { GCACGTCAAGACTGTCAAGG }\end{array}$ & This work \\
\hline $\begin{array}{l}\text { KmTF } \\
\text { KmTR }\end{array}$ & $\begin{array}{l}\text { CAGAAAGTAATATCATGCGTCAATCG } \\
\text { AGCTCGGTACCTCGATGATAAG }\end{array}$ & This work \\
\hline $\begin{array}{l}\text { SCF1 } \\
\text { SCR1 }\end{array}$ & $\begin{array}{l}\text { GGACTCTGGACATGCAAGAT } \\
\text { ATACCCTTCTTAACACCTGGC }\end{array}$ & [30] \\
\hline
\end{tabular}

561 
564 Table 2. Concentration values and UV parameters (ratios at 260/280 and 260/230 nm) of DNA

565 extracts obtained under optimized extraction conditions from different wine samples.

566

\begin{tabular}{|l|l|c|c|c|}
\hline \multicolumn{1}{|c|}{ Yeast strain } & \multicolumn{1}{|c|}{ Wine sample } & $\mathbf{C}(\boldsymbol{\mu g} / \boldsymbol{\mu l})$ & $\mathbf{O D}_{\mathbf{2 6 0 / 2 8 0}}$ & OD $_{\mathbf{2 6 0} / 230}$ \\
\hline $\begin{array}{l}\text { EC1118 } \\
\text { (conventional) }\end{array}$ & Must 1 & 2.43 & 1.93 & 2.10 \\
\cline { 2 - 5 } & Must 2 & 2.72 & 1.89 & 2.20 \\
\cline { 2 - 5 } & Must 3 & 2.67 & 1.90 & 1.85 \\
\hline \multirow{2}{*}{$\begin{array}{l}\text { EKD-13 } \\
\text { transgenic) }\end{array}$} & Must 1 & 0.80 & 1.99 & 2.45 \\
\cline { 2 - 5 } & Must 2 & 0.67 & 1.84 & 1.80 \\
\cline { 2 - 5 } & Must 3 & 1.72 & 1.92 & 2.14 \\
\hline
\end{tabular}




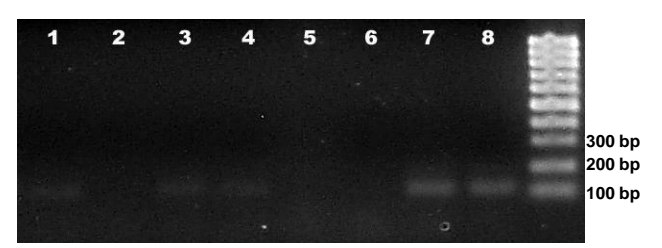

569

Figure 1 


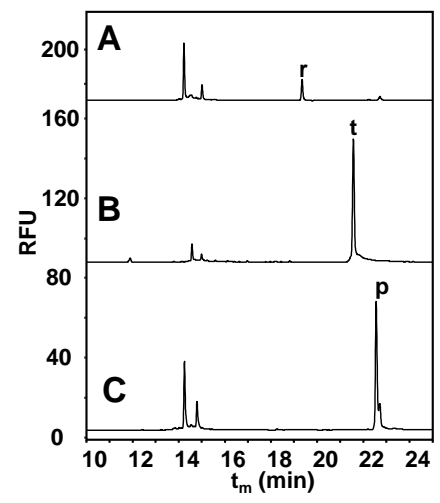

Figure 2 


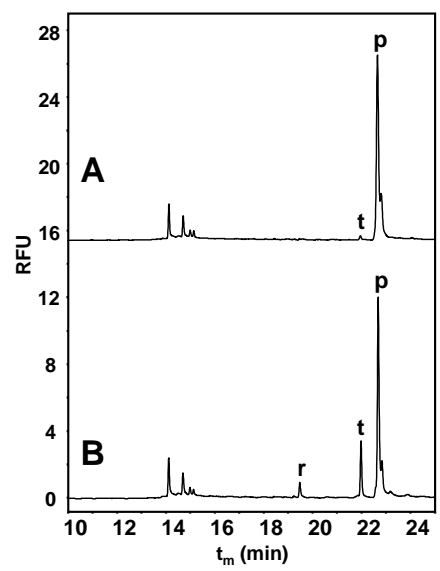

Figure 3 


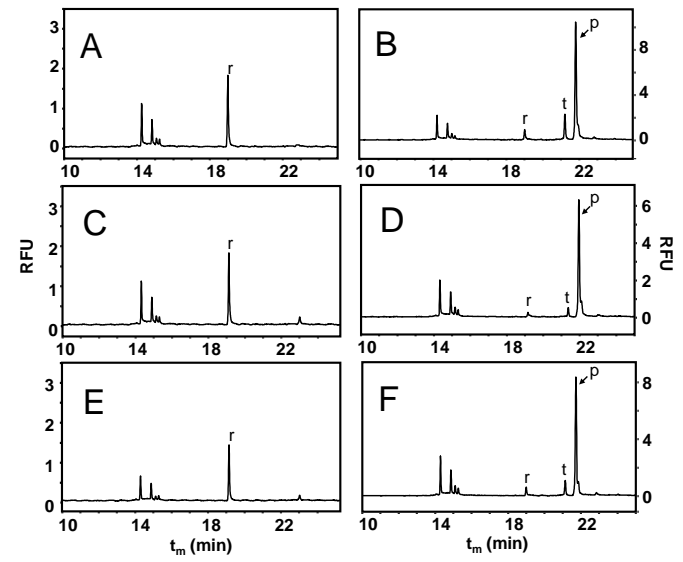

Figure 4 